\title{
Construction of a High-density Genetic Linkage Map and QTL Analysis of Resistance to Cucumber Mosaic Virus in Luffa cylindrica (L.) Roem. Based on Specific Length Amplified Fragment Sequencing
}

\author{
Lina Lou ( $\sim$ linabeibei@163.com ) \\ Institute of Vegetable Crops, Jiangsu Academy of Agricultural Sciences \\ Zhe Liu \\ Institute of vegetable crops, Jiangsu Academy of Agricultural Sciences \\ Xiaohong Liu \\ Institute of Vegetable Crops, Jiangsu Academy of Agricultural Sciences \\ Xiaojun Su \\ Institute of Vegetable Crops, Jiangsu Academy of Agricultural Sciences
}

\section{Research article}

Keywords: Luffa cylindrica L., Cucumber mosaic virus (CMV), high-density genetic map, SNPs, QTL analysis

Posted Date: October 10th, 2019

DOI: https://doi.org/10.21203/rs.2.15852/v2

License: () (1) This work is licensed under a Creative Commons Attribution 4.0 International License. Read Full License 


\section{Abstract}

Background: Luffa cylindrica L. is an economically important vegetable crop that is consumed globally. Cucumber mosaic virus (CMV) is an important virus affecting Luffa spp. No specific high-density maps have been constructed owing to a lack of efficient markers. Furthermore, no genes or quantitative trait loci (QTLs) are reportedly responsible for CMV resistance in Luffa spp. The development of next-generation sequencing has enabled discovery of single nucleotide polymorphisms and high-throughput genotyping of large populations.

Results: A total of $271.01 \mathrm{Mb}$ pair-end reads were generated. The average sequencing depth was $86.19 \times$ in both maternal and parental lines, and $14.57 \times$ in each $F 2$ individual. When filtering low-depth specific locus amplified fragment (SLAF) tags, 100,077 high-quality SLAFs were detected, and 7,405 of them were polymorphic. Finally, 3,701 of the polymorphic markers were selected for genetic map construction, and 13 linkage groups were generated. The map spanned $1,518.56 \mathrm{cM}$ with an average distance of $0.41 \mathrm{cM}$ between adjacent markers. Our results also revealed that CMV resistance was regulated by QTLs. Based on the newly constructed high-density map, two loci located on chromosome 1 (100.072 100.457 cM) and 4 (42.475 44.398 cM) were identified to regulate CMV resistance in L. cylindrica . A gag-polypeptide of LTR copia-type retrotransposon was predicted as the candidate gene responsible for CMV resistance in L. cylindrica . Conclusions: A high-density linkage map of L. cylindrica was constructed using SLAF. QTL mapping based on CMV disease phenotypes of F 2 led to the identification of two QTL on chromosome 1 and 4, respectively. Kompetitive allele-specific PCR analysis of $60 \mathrm{~F} 2$ individuals, which gave rise to F 2:3 individuals, was carried out. We found that the QTL on chromosome 1 was associated with CMV resistance. Mapping of CMV QTL combined with the transcriptomic sequence alignment identified a gag-polypeptide of LTR copia-type retrotransposon as the most likely causal gene.

\section{Background}

Luffa spp. $(2 n=26)$, which belongs to the family Cucurbitaceae, is widely cultivated in tropical and subtropical regions, such as China, Malaysia, India, Korea, Thailand, Central America, and Africa [1, 2]. Among the nine Luffa species found worldwide, only Luffa cylindrica (L.) Roem. and L. acutangula (L.) Roxb. are domesticated [2,3]. Furthermore, L. cylindrica has always been a preferred crop for cultivation because of its higher fruit set and bigger fruit size [4]. This species is grown principally for production of sponges, which can be used as bath sponges, or as an alternative biomaterial used for packaging, furniture, and plastic appliances, and also as an adsorbent of heavy metal contaminants from industrial waters, which makes it a cash crop [4-6]. The immature fruits are used as a vegetable and are rich in various nutrients [7]. Its medicinal value has also been reported [8, 9].

High-density genetic linkage maps play an important role in genome assembly, gene/ quantitative trait locus (QTL), fine mapping, and map-based gene cloning. One major requisite for high-density genetic map construction is the availability of a huge amount number of polymorphic markers. In $L$ uffa spp., research concerning genetic linkage maps has only started recently, using sequence related amplified polymorphism (SRAP) markers. Cui et al. (2015) constructed an interspecific genetic linkage map using an $\mathrm{F}_{2}$ population derived from a cross between $L$. acutangula (L.) Roxb. and $L$. cylindrica (L.) Roem [10]. Although this map was the first genetic linkage map of Luffa spp, 24 linkage groups more than 13 chromosomes were construct in Cui's study. Wu et al. (2016) constructed a more condensed interspecific genetic map, which consists of 177 EST-SSR markers distributed in 14 linkage groups (LG) with an average of $102.58 \mathrm{cM}$ per LG [11]. Due to interspecific hybridization, there was a marked segregation distortion of molecular markers in this map. The markers were not well-distributed over the LGs. To our knowledge, based on L. cylindrica (L.) Roem genetic background, no higher-density genetic maps have been constructed with markers distributed evenly in the 13 chromosomes. The lack of abundant, stable, and polymorphism molecular markers, such as single nucleotide polymorphisms (SNPs), hampers the construction of high-density genetic maps.

With the advent of next-generation sequencing (NGS) technology, such as specific locus amplified fragment sequencing (SLAF-seq), it is now feasible to develop SNP markers on a large scale, which is useful for constructing a genetic map. With various advantages, such as its high-throughput, high accuracy, and low-cost, this technique has been employed for high-density genetic map construction in many species, such as common carp [12], sesame [13], soybean [14, 15], Prunus mume Sieb. et Zucc [16], cucumber [17, 18], wax gourd [19], and sweet osmanthus [20]. Moreover, SLAF-seq based genotyping does not depend on a reference genome sequence, which makes it particularly important for species without a sequenced genome, such as Luffa spp.

Cucumber mosaic virus (CMV) belongs to the Cucumovirus genus of the family Bromoviridae, which can be transmitted via >1200 plants and 60 aphid species [21]. Although several genotypes of $L$. acutangula have been found to be resistant to CMV [22], the genetic mechanism of their resistance is still unclear. In our study, SLAF-seq was employed to construct an SNP-based genetic map for L. cylindrica (L.), which spanned 1,518.56 cM, with an average of $0.41 \mathrm{cM}$ among adjacent markers, and consisted 3,701SNP markers distributed on 13 linkage groups. In addition, the QTLs associated with CMV resistance were mapped by using this genetic map, certified the usefulness of it. Furthermore, a gag-polypeptide of LTR copia-type retrotransposon as a candidate gene for such QTL was also predicted in this study. To our knowledge, this is the most high-density genetic map of Luffa spp. to date. The SNP markers and the genetic map reported in this study could prove to be valuable resources for future research. This is also the first report on detection of $\mathrm{CMV}$ resistanceassociated QTLs and prediction of related candidate genes in L. cylindrica (L.).

\section{Results}

\section{SLAF sequencing and genotyping}

SLAF-seq is an efficient approach for large-scale genotyping, which is based on high-throughput sequencing technologies, and which could be applicable to various species and populations. DNA was isolated from parental genotypes 'P1-21' and 'P2-16', and $130 \mathrm{~F}_{2}$ individuals generated by a cross between these genotypes, and used to create SLAF libraries. SLAF-seq yielded $271.01 \mathrm{M}$ clean, trimmed 100 bp paired-end reads, among which the guanine-cytosine (GC) content was $39.58 \%$ and $Q 30$ ratio (the ratio of reads with a quality score of $>30$ ) was $89.16 \%$. 
All SLAF pair-end reads were clustered based on sequence similarity, and sequences with over $90 \%$ identity were grouped as one SLAF locus. Table 1 shows an overview of the average degree of SLAFs and the SLAF sequencing depth in both parental lines and the $F_{2}$ population. SLAFs containing more than four tags and sequence depth less than 213 were filtered out as repetitive and low-depth SLAFs, respectively. Only the SLAFs with $2-4$ tags were identified as polymorphic SLAFs. Finally, in this study, a total of 100,077 high-quality SLAFs were detected, among which 14,918 were polymorphic (14.91\%) (Additional file 1). After filtering out markers lacking parental locus information among the polymorphic SLAFs, 11,788 markers were screened for genetic construction. Following the genotype encoding rule, the 11,788 SLAFs were classified into eight segregation patterns ( $a b \times c d, e f \times e g, h k \times h k, I m \times l l, n n \times n p, a a \times b b, a b \times$ $\mathrm{cc}$, and $\mathrm{cc} \times \mathrm{ab}$ ) (Fig. 1). Due to the homozygous genetic background of the two parental lines (P1-21 and P2-16), aa $\times$ bb segregation pattern was needed to follow.

There were 7,404 of 11,788 polymorphic SLAF markers followed the aa $\times$ bb segregation pattern, and were further selected to constructed the linkage map (Fig. 1). While SLAFs markers with parental sequence depth of less than 10x, completeness less than $70 \%$, and/or significant segregation distortion ( $\mathrm{p}$-value $<0.001$ ), were considered as low-quality and should be filtered. Then, 3,701 markers were finally selected for genetic map construction.

\section{High-throughput linkage map construction and evaluation}

After High Map linkage analysis (Liu et al., 2014), the 3,701 markers were mapped on 13 linkage groups (LGs) (Table 2, Fig. 2, Additional file 2). The average integrity of the mapped markers was $99.18 \%$ (Additional file 3). Detailed information of this genetic map is presented in Additional file 4 and Table 2.

The map consisted a total of 1,518.56 cM with an average distance of $0.41 \mathrm{cM}$ among adjacent markers. The biggest and smallest LG was LG1 and LG10, which contained 380 and 98 markers, respectively. On average, there were 285 SLAF markers per LG. The length of individual LGs varies form $143.28 \mathrm{cM}$ (LG 9) to $91.71 \mathrm{cM}(\mathrm{LG} 8)$, with the average intermarker distance ranging from $0.30 \mathrm{cM}$ (LG 7) to $1.16 \mathrm{cM}$ (LG 10). Furthermore, the maximum distance between markers among the 13 LGs ranged from $2.77 \mathrm{cM}$ (LG 7) to $4.86 \mathrm{cM}$ (LG 10) (Table 2).

Haplotype and heat maps were used to evaluate the quality of the newly constructed genetic map. The double crossovers in the mapping population showing in haplotype maps indicated the errors in genotyping. the relationship of recombination among markers on the same linkage group was reflected in the heat map, and can be used to find potential sorting errors of markers.

By using 3,701 SLAF markers, haplotype maps were generated for each of the $F_{2}$ individuals and the parental controls, which can intuitively display the recombination events within each individual as previously described [23] (Additional file 5). In this study, most of the recombination blocks were clearly defined and the percentage of double crossovers in all of the linkage groups was less than $0.18 \%$ (Table 3 ), which was lower than the describe of usually less than $3 \%$ [19]. Heat maps were also generated by using pair-wise recombination values for the 3,701 SLAF markers (Additional file 6). The SLAF markers in most LGs were well ordered.

\section{QTL mapping and validation of SNP markers using KASP assay}

The parental line P2-16 showed resistance to the CMV isolate, characterized by only subtle symptoms after CMV infection. Most P2-16 plants scored 1 or 3 and only one out of ten scored 0 (average 1.3). Most P1-21 plants scored 7 and only one got a score of 5 and other two plants got 9 (average 7.2 ). All $F_{1}$ plants scored 3 or 5 (average 4.4) (Fig. 3a). The disease rating of parental lines and their $\mathrm{F}_{1}$ progeny suggested that the resistance to $\mathrm{CMV}$ in $\mathrm{P} 2-16$ might be incompletely dominant. In the segregating $F_{2}$ population, plants that were neither completely immune (disease score 0 ) nor severely infected (disease score 9 ) were found. The disease grades of $F_{2}$ plants were more or less equally distributed over 1,5 , and 7 , whereas a slightly lower number of individuals scored 3 (Fig. 3b). If we consider plants with disease grade 1 as resistant, grades 3 and 5 as intermediately resistant, and grade 7 as susceptible, then among the 130 $F_{2}$ plants, 34 individuals were resistant to CMV, 61 were intermediately resistant, and 35 were susceptible $\left(X^{2}=0.507\right.$ for $\left.1 R: 2 M R: 1 S\right)$. Therefore, we concluded that the resistance of genotype P2-16 to CMV cannot be explained by one single resistance gene. Sixty $\mathrm{F}_{2}$ plants, including 30 resistant (29 plants scored as 1 , and one as 3 ) and 30 susceptible plants (all scored 7 ), were chosen to produce $F_{2: 3}$ progenies. When we compared the disease index of $F_{2: 3}$ progenies generated from the resistant and susceptible $F_{2}$ groups, we found that they were extremely significant, which indicated that the disease index of $F_{2: 3}$ progenies corresponded to the disease score of their $F_{2}$ plants. The disease rating in the $F_{2: 3}$ populations from $60 F_{2}$ single plants also showed a lower distribution on disease indices $33.4 \sim 55.6 \%$, suggesting that the resistance to CMV in P2-16 was regulated by multiple quantitative genes (Fig. 3c).

Based on the high-density genetic map and phenotypic data of CMV resistance in the $\mathrm{F}_{2}$ population, QTL mapping of CMV resistance was performed by Join Map 4.0 with the Kosambi mapping function. The threshold of significance $(P=0.05)$ for each marker after 1,000 permutations was set to 5.0 and based on logarithm of odds (LOD) 3.0 intervals, which identified two loci at $100.072 \sim 100.457 \mathrm{cM}$ and $42.475 \sim 44.398 \mathrm{cM}$ on LG 1 and LG 4, respectively (Fig. 4, Additional file 7). On LG 1, the genetic distance of markers in the flanking regions of CMV resistance loci included three markers at $100.072 \mathrm{cM}$ and 27 markers at $100.457 \mathrm{cM}$. (Additional file 7). The estimated proportion of phenotypic variance explained by the locus at LG1 was 7.48-8.41\%. On LG 4, only one marker was significantly linked to CMV resistance, explaining $9.75 \%$ of the phenotypic variance (Additional file 7 ).

To validate the QTL identified by SLAF-seq, a kompetitive allele-specific PCR (KASP) assay was used for genotyping. All the SLAF markers in the two loci intervals were considered to develop KASP marker. However, due to the lack of genomic database, not all the SLAF marker sequences were suitable to design KASP markers. Finally, only six significant markers on LG 1 for the KASP assay were identified successfully (Table 4 and 5, Fig 5). As to the loci on LG 4, sequences were unable to reveal KASP markers. The disease index from the $F_{2: 3}$ populations was used to represent the phenotypic values of individual $F_{2}$ plants in KASP analysis. All the KASP markers at 100.457 cM on LG 1 were significantly associated with CMV resistance in the 60 extremely resistant and susceptible $F_{2}$ plants with the phenotypic values from their pedigrees (Table 5). 


\section{Transcript sequencing and candidate gene prediction}

To predict which genes were related to CMV resistance in L. cylindrica, a transcript sequencing database was built using the parental lines after CMV inoculation. The interval of marker sequences on LG1 (98.534 119.689 cM) and LG4 (42.475 54.66 cM) were chosen to conduct BLAST searches, including the markers most significantly linked to CMV resistance. The candidate genes were identified by alignment searches of mapped QTL marker sequences against the translated L. cylindrica reference database (Supplementary data sheet 4). By pfam, Swissprot, and nr annotation, zinc-binding in reverse transcriptase, retrovirus-related Pol polyprotein from transposon, probable disease resistance protein, serine hydrolase (FSH1), serine/arginine-rich splicing factor, and histidine kinase responded to the CMV inoculation in L. cylindrica. Retrovirus-related Pol polyprotein (gag-polypeptide of LTR copia-type; gag-preintegrase domain) was most frequently identified in this study (Additional file 8).

Expression of the identified L. cylindrica defense gene annotation in the RNA-seq dataset was analyzed between treatments within each genotype and between genotypes within both treatment groups. The gene predicted by three markers (Marker 33125 on 98.534, Marker 18364 on $100.457 \mathrm{cM}$, and Marker 921 on $106.611 \mathrm{cM}$ ) on LG1 was downregulated in CMV-inoculated plants in both susceptible and resistant parents, with no difference between genotypes during disease development. Marker 31030, marker 36013, and marker 42619 were downregulated in susceptible parent plants only at 2 days after CMV inoculation, when compared to the plants without inoculation; in resistant parental plants, marker 31030 and marker 36013 were downregulated comparing R0 with R6, while both were downregulated after inoculation, and they were observed to be downregulated when comparing R0 with R2, and upregulated when comparing R2 with R6. There was no significant difference between parental lines among both marker 31030 and marker 36013 , while marker 42619 was upregulated. For marker 68384, there were no changes in expression in the susceptible plants, but a downregulation was observed in CMV-resistant plants. For marker 65023 , no changes in expression were observed between treatments within each genotype or between genotypes within both treatment groups (Additional file 8). Due to lack of expression data, we did not analyze the other markers on LG1. Only markers on $100.457 \mathrm{cM}$ were significant to CMV resistance in this interval. Although markers in interval $42.475 \sim 54.66 \mathrm{cM}$ on LG4 were annotated to retrovirus-related Pol polyprotein, only marker 52122 was present on the QTL mapping interval. Due to inadequate expression data, the prediction on LG4 was not convincing.

\section{Discussion}

\section{Saturated SNP-based high-density genetic linkage map in Luffa}

Genetic linkage maps are useful tools for fine mapping and map-based cloning [17, 24, 25]. Two interspecific genetic maps have previously been constructed in Luffa $[10,11]$. Cui et al. (2015) reported the first sponge gourd genetic linkage map, which was constructed using SRAP markers [10]. Due to the low accuracy of SRAP markers, this map was not efficient to be used in the subsequent study of genes or QTL mapping. Whereas there are 13 pairs of chromosomes in Luffa, the genetic linkage map constructed by Cui et al. (2015) contained 24 small linkage groups, due to segregation distortion of molecular markers caused by the interspecific hybridization [10].

By using more accurate and stable extended sequence tag-simple sequence repeats (EST-SSR) markers through transcriptome sequencing, Wu et al. (2016) constructed a more comprehensive interspecific Luffa genetic linkage map with 177 EST-SSR markers distributed on 14 linkage groups [11]. Although the fact that an interspecific Luffa cross was used for this map ensures a wide genetic diversity, the distant relationship between the two parental lines and subsequent high level of segregation distortion caused an uneven marker distribution on the chromosome. Some linkage groups only contain a limited number of markers, hindering the utilization of this map in map-based cloning.

Some studies have indicated that genetic diversity within single Luffa species is narrow [26]. This situation would cause a low polymorphism rate for molecular markers, which then makes it difficult to construct a high-density genetic map in Luffa cylindrica. With the rapid development of sequencing technology, SLAF-seq is a good strategy for high-throughput SNP discovery and genotyping, especially for species for which there is no reference genome available, such as Luffa spp.

In the present study, we employed SLAF sequencing technology to obtain novel markers in Luffa cylindrica for linkage map construction and QTL mapping. In total, $271.01 \mathrm{Mb}$ pair-end reads were generated, which corresponded to 100,077 high-quality SLAFs. Among them, 7,405 of SLAFs were polymorphic (7.4\%). Eventually, 3,701 polymorphic markers were used to construct a genetic map, which contained 13 LGs. This map spanned 1,518.56 cM with an average distance of $0.41 \mathrm{cM}$ between adjacent markers.

Cui et al. (2015) [10] and Wu et al. (2016) [11] used interspecific Luffa spp. crosses for their genetic maps, whereas we used an intraspecific Luffa cylindrica $\mathrm{F}_{2}$ mapping population in our study, which avoided the marked segregation distortion of molecular markers in interspecific hybridization populations. Furthermore, we were able to select more polymorphic markers with high accuracy and stability, distributed uniformly over the whole genome. To our knowledge, this is the first high-density genetic linkage map in Luffa cylindrica. This could be a useful starting point for further genetic studies on this plant species.

\section{QTL analysis of CMV resistance in Luffa}

CMV causes serious diseases in a broad range of host plants globally. It is difficult to eradicate CMV by pesticides. Using CMV-resistant crop varieties is an economical and durable approach to defend against this virus. CMV is a very complex disease, symptoms of which can be affected by plant age, virus strain, environment, and inoculation methods, complicating the evaluation of promising genetic materials [27]. The study on CMV resistance in Luffa spp. is at its early stages. Rani et al. recently reported 12 genotypes of ridge gourd [ $L$. acutangula (L.) Roxb], which were found to be resistant to CMV, being completely symptomless after inoculation [22]. To our knowledge, this is the only study on CMV resistance in Luffa spp. 
The genetics of resistance to CMV are varied among species, comprising dominant, recessive, monogenic, and polygenic genes or QTLs. Monogenic dominant resistance genes have been identified, such as RCY in Arabidopsis thaliana C-24 [28], RT4-4 in common bean [29], and Cmr 1 in pepper [30]. In Arabidopsis, two independent recessive genes (cum1 and cum2) were also identified to be involved in translation and movement of the CMV virus [31,32]. CMV resistance in chili pepper (Capsicum annuum L.)was also found to be regulated by multiple genes and/or QTLs in pepper [33-35]. In potato, CMV resistance was reported to be regulated by one major QTL and several minor QTLs [36]. Among cucurbits, like cucumber, a study of the genetics of resistance to CMV in Cucumis sativus var. hardwickii revealed that it was regulated by a single recessive gene [37]. In melon, resistance to CMV in the Korean accession PI161375 (SC) was initially described as oligogenic, recessive [38], and quantitative [39], with a major QTL, named $c m v 1$, which was in fact a single gene responsible for resistance to some CMV strains, providing full resistance to strains P9 and P104.82. Another study [40] found that the resistance to CMV in melon SC was governed by one gene and at least two quantitative trait loci, the single gene, cmvqw12.1, co-located with cmv 1 in linkage group (LG) XII, two QTLs in LGIII (cmvqw3.1) and LGX (cmvqw10.1) and showed interaction between cmvqw12.1 and cmvqw3.1. Due to the lack of sufficient molecular markers and adapted genetic linkage map, no resistance gene or QTL has yet been mapped.

Presently, we employed SLAF-seq to construct the high-density genetic map in sponge gourd (Fig. 3). SLAF-seq is a low-cost, efficient high-throughput sequencing based technique, and does not depend on the availability of a reference genome sequence. SLAF-seq is a high-throughput technique that promoted the detection speed of QTLs associated with CMV resistance. L. cylindrica genotype P2-16 was found to exhibit partial CMV resistance. We were able to identify two QTLs underlying the resistance to CMV on linkage groups 1 and 4 . These QTLs could explain $8.41 \%$ and $9.75 \%$ of the phenotypic variance respectively, with the LOD values of 3.56 and 3.28. The QTL on LG 1 was verified in subsequent $F_{2: 3}$ lines using KASP markers developed based on the SLAF sequences.

The high-density L. cylindrica genetic map constructed in this study could serve as a valuable tool in many ways, such as gene mapping, marker-assisted breeding, map-based gene cloning, comparative mapping, and draft genome assembling. Furthermore, the resistance of CMV were mapped by using the highgenetic map constructed in this study, which certified the utility of it. Single type of segregated population and inefficiency of derived progeny may affect the detection of QTLs. Stable genetic populations, such as recombinant inbred lines (RILs), might be developed in the next step, which might lead to the detection of more QTLs.

\section{Annotation of gene function of mapping intervals}

Plants have evolved a series of mechanisms for defense against viral infections. Three main components were developed to confer resistance to CMV in plants, including restriction of virus installation in the host cells [41, 42], restriction of virus multiplication in the whole plant [43], and restriction of longdistance movement [44]. The most well-known examples are the studies that identified the eukaryotic translation initiation factors 4E(iso) (Eif(iso)4E) and $4 \mathrm{E}(\mathrm{elf} 4 \mathrm{E})$ as the host factors required for potyvirus multiplication, which directly interacts with the viral factor of potyviral genome-linked protein (VPg) [45]. elF4E and elF(iso)4E are recessive genes conferring resistance to viruses through the viral-encoded protein VPg [46-50]. Resistance to RNA virus has been validated by silencing of the eif4E gene in tomato, melon, and cucumber [51-53]. QTLs, involved in the restriction of CMV in pepper, were also found to be associated with partial restriction of CMV long-distance movement [34]. A phloem protein in cucumber has also been reported to be involved in long-distance movement of CMV [54].

The plants attacked by the virus activate defenses at different levels. At first, they activate basal defenses involving pathogen-associated molecular patterns (PAMPs), which are recognized by plant transmembrane receptors [55]. In addition, some plants exhibit a second line of defense, known as effector-triggered immunity (ETI), to counter pathogens that have evaded the basal defenses [56]. In this step, genes associated with ETI, known as resistance (R) genes, such as nucleotide-binding site (NBS) and leucine-rich repeats (LRRs), are activated [55,56]. The RCY1 gene in A. thaliana [28,57], and RT4-4 in common bean [29], are NBS-LRR type genes against CMV. In addition to these R genes, RNA silencing plays a role in antiviral responses, including Dicer-like (DCL) proteins (DCL2/4) along with ARGONAUTE(AGO) protein AG01/2 [58-61], RNA-dependent RNA polymerase 1 (RDR1/6) (59,62,63), and ENOR3[64], in Arabidopsis thaliana.

In this study, retrovirus-related Pol polyprotein (gag-polypeptide of LTR copia-type), which exhibits high similarity to the retrotransposon Tnt 1-94 of Nicotiana tabacum, was identified in the CMV resistance mapped location (Additional file 8). Retrotransposons are mobile genetic elements closely related to retroviruses [65]. Both types of elements share structural characteristics and are functionally related. The expression of the Tnt 1-94 element has been studied in detail and shown to be induced in association with plant defense mechanisms [66-68]. We speculated that the retrovirus-related Pol polyprotein plays an important function in Luffa spp. against CMV virus. Furthermore, a probable disease resistance protein At4g27220 in A. thaliana or At4g27190-like in Cucumis melo, serine hydrolase (FSH1), and serine/arginine-rich splicing factor, RSZ21, in A. thaliana were predicted very near to the mapped location. Conversely, the annotation of gene function of mapping intervals in this study also validated the effectiveness of the mapped QTLs.

\section{Conclusion}

In this study, we performed SLAF-seq on an $\mathrm{F}_{2}$ population of L. cylindrica. A high-density genetic map was constructed, which spanned 1,518.56 cM with an average distance of $0.41 \mathrm{cM}$ between adjacent markers. Two QTLs on LG 1 and 4 of CMV resistance were mapped based on this map, and QTL on LG 1 was verified by KASP markers. Based on the search of the sequences of the linked markers in an RNA-seq database, candidate genes were predicted to be likely a gag-polypeptide protein of LTR copia-type retrotransposon. Thus, we concluded that the QTLs on LG 1 and 4 most likely represent a retrovirus-related Pol polypeptide (gag-polypeptide of LTR copia-type) with resistance activity towards CMV in Luffa spp.

\section{Methods}




\section{Plant material and genomic DNA extraction}

Two advanced inbred lines of $L$. cylindrica (L.) Roem., 'P1-21' and 'P2-16', were selected as parental genotypes. 'P1-21' has palmate leaves and short sticktype immature fruit, and is susceptible to CMV. 'P2-16' has palmate deep cleft leaves and long stick-type immature fruit, and is resistant to CMV. To investigate the inheritance and to map the CMV resistance in L. cylindrica, a cross was made between 'P1-21' (female parent) and 'P2-16' (pollen donor) to create an $F_{1}$ population in 2014. The $F_{1}$ individuals were self-pollinated to generate an $F_{2}$ population in 2015 . One hundred and thirty $F_{2}$ individuals were used as the mapping population. After inoculation with $C M V$ and recording of the phenotype, $F_{2}$ individuals were self-pollinated to generate $F_{2: 3}$ lines in 2016 . Only $60 \mathrm{~F}_{2}$ individuals gave rise to $\mathrm{F}_{2: 3}$ populations, as the other $70 \mathrm{~F}_{2}$ individuals either died during the growing season or only had female or male flowers in one plant, which led to no self-progeny production.

Seedlings of the offspring and parents were planted in a greenhouse of the Vegetable Research Institute, Jiangsu Academy of Agricultural Sciences, Nanjing, China. Young healthy leaves from the two diploid parents as well as $\mathrm{F}_{2}$ individuals were immediately frozen in liquid nitrogen and stored in a $-80{ }^{\circ} \mathrm{C}$ freezer. Total genomic DNA was extracted from each leaf sample using the cetyltrimethylammonium ammonium bromide method [69]. DNA quality was evaluated by $1 \%$ agarose gel electrophoresis, and the concentration was estimated using a NanoDrop Spectrophotometer (Thermo Fisher Scientific, USA).

\section{CMV disease evaluation}

The CMV isolate used in this study was $\mathrm{CMV}_{\mathrm{FNY}}$ provided by Dr. Guo of the Institute of Vegetable crops, Jiangsu Academy of Agricultural Sciences. Response of $F_{2}$ population (130 individuals) to $C M V$ inoculation was evaluated in a climate-controlled chamber in the lab in Nanjing, China in 2016 . The $F_{2: 3}$ individuals (60 lines) were evaluated in 2017. The $\mathrm{F}_{2: 3}$ families were arranged in a randomized complete block design with three replicates, and each replicate had ten plants. The parental lines and F1 plants were included in all experiments.

CMV was inoculated as previously described [37] with minor modifications. The CMV inoculum was isolated from infected leaves of Nicotiana benthamiana and $1 \mathrm{~g}$ of infected leaves was ground in $5 \mathrm{~mL}$ of $0.02 \mathrm{M}$ phosphate buffer ( $\mathrm{pH} 7.2$ ). The sap was rub-inoculated using a pestle dusted with carborundum powder (600 mesh), at the 3-4 true leaf stage. After 5 min, the excess sap was washed off with distilled water. After inoculation, luffa seedlings were kept in a climate-controlled incubator maintained at 26 to $28^{\circ} \mathrm{C}$. Inoculated seedlings began to show symptoms after 1 week, and the disease grade of luffa plants was recorded at 3 weeks' post-inoculation.

Each plant was examined visually and assigned a disease grade based on the severity of mosaic and leaf distortion on a scale of 0 to 9 [70]. Disease grades were assigned as follows: 0 = no symptoms, 1 = a very mild mosaic and puckering on inoculated leaf, or few light and dark green areas associated with vines, $3=$ mosaic, blistering, and puckering of leaves on the upper parts of the plant, $5=$ strong mosaic and mild leaf distortion on the upper parts of the plant, $7=$ severe leaf mosaic and distortion, mild stunting, 9 = severe stunting and leaf death (Fig. 6). Disease indices of a population were calculated from disease grades of individual plants in that population, according to the formula: disease indices $(\mathrm{DI})=\neg(\Sigma$ number of plants in the disease grade $\times$ disease grade $) /(9 \times$ total number of plants) $\times 100$ [35].

\section{SLAF library construction and high-throughput sequencing}

The SLAF library construction and high-throughput sequencing were conducted as described by Sun et al. with few modifications [12]. The DNA samples of the $130 \mathrm{~F}_{2}$ progenies and two parents were treated with two restriction enzymes, i.e. Haelll and Hpy166II (NEB), to digest the genomic DNA. Subsequently, a single nucleotide $(A)$ overhang was added to the digested fragments using Klenow Fragment $\left(3^{\prime} \rightarrow 5^{\prime}\right.$ exo-) (NEB) and dATP at $37^{\circ} \mathrm{C}$. Then, duplex tag-labeled sequencing adapters (PAGE-purified, Life Technologies, USA) were ligated to the A-tailed fragments using T4 DNA ligase (NEB). Polymerase chain reaction (PCR) was performed using diluted restriction-ligation DNA samples, dNTP, Q5® High-Fidelity DNA polymerase, and PCR primers (Forward primer: 5'AATGATACGGCGACCACCGA-3', reverse primer: 5'-CAAGCAGAAGACGGCATACG-3') (PAGE-purified, Life Technologies). The PCR products were then purified and separated on a $2 \%$ agarose gel. Fragments with 300 to 500 base pairs (with indexes and adaptors) in size were excised and purified using a QIAquick gel extraction kit (Qiagen, Germany). Gel-purified products were diluted for sequencing. Then, pair-end sequencing (each end $125 \mathrm{bp}$ ) was performed on an Illumina HiSeq 2500 system (Illumina, Inc., USA) at the Biomarker Technologies Corporation in Beijing.

\section{SLAF-seq data analysis and genotyping}

SLAF marker identification and genotyping were performed as previously described [12]. Low-quality reads in each cycle (quality score < 30; a quality score of 30 represents a $0.1 \%$ chance of error) were discarded by real-time monitoring during sequencing. Then, all SLAF paired-end reads with clear index information were detected by BLAT (-tileSize $=10-$ stepSize $=5$ ) [71]. The sequences with $>90 \%$ similarity were grouped and identified as one SLAF locus.

In mapping populations of diploid species, such as $L$. cylindrica, one locus can contain at most four genotypes. Thus, the groups containing more than four tags were filtered out as repetitive SLAFs. Only the individuals that contained fewer than four tags, had an average sequence depth of 20 -fold or more in the parents and 8-fold or more in the progenies, and exhibited $>70 \%$ integrity in mapping population individuals were identified as high-quality SLAFs, and SLAFs containing 2 to 4 tags were considered as polymorphic markers. Polymorphic SLAF markers were classified into eight segregation patterns as follows: ab $\times$ cd, ef $\times$ eg, hk $\times h k, I m \times I I, n n \times n p, a a \times b b, a b \times c c$, and $c c \times a b$. The alleles of each SLAF locus were defined according to the parental genotypes, and individuals were genotyped by sequence similarity to their parents [12]. Since the $F_{2}$ population was derived from two homozygous parents with a genotype of aa or bb, only the SLAF markers with segregation patterns of aa $\times$ bb was selected for subsequent map construction. 


\section{Linkage map construction}

The modified LOD (MLOD) scores were calculated for the high-quality SLAFs from the $F_{2}$ population, which can be used for linkage clustering. Prior to ordering, markers with MLOD score $<5$ were filtered out. Map construction was achieved according to the method of High Map, as previously explained [72]. First, the markers with high qualities were grouped based on a pair-wise MLOD score for the recombination frequency. Second, those markers were ordered using Gibbs sampling, spatial sampling, and a simulated annealing algorithm. At the same time, the map distance was estimated. Third, the incorrect genotypes were recognized and eliminated through the k-nearest neighbor algorithm. Marker ordering and error correcting were carried out iteratively so that the markers could be ordered correctly. Several cycles later, accurate linkage maps were achieved. The map function of Kosambi was used in the process. At last, heat maps and haplotype maps were used to evaluate the map quality.

\section{Mapping of CMV resistance genes and KASP assay}

The phenotypic data on CMV resistance were collected as described above. Linkage analysis of the CMV resistance gene loci with SLAF markers was performed with the Kosambi mapping function of JoinMap 4.0 (Kyazma, NL).

SNP markers associated with CMV resistance identified by SLAF-seq were validated using a KASP assay. For each marker, two allele-specific primers (one for each SNP allele) and one common (reverse) primer were designed for each KASP assay using a tool provided by LGC Genomics (www.lgcgenomics.com) based on the SNP locus sequence. The KASP assays were designed by LGC Genomics and carried out according to the company's protocol (http://lgcgenomics.com).

\section{RNA extraction, transcript sequencing, and candidate gene prediction}

For RNA extractions, plants of parental lines were inoculated with CMV as described above. At 0, 2, and 6 days' post-inoculation, leaves of three biological replicates per genotype and treatment combination were sampled and stored at $80^{\circ} \mathrm{C}$. Total RNA was isolated using the RNeasy Kit (Qiagen, Germany), and RNA samples were shipped on dry-ice to Biomics (Beijing) Biotech Co. Ltd.

Poly (A) mRNA was isolated using oligo-dT beads (Qiagen, Germany). The mRNA was broken into short fragments of approximately 300 nt. First-strand cDNA was synthesized using random hexamer-primed reverse transcription. Second-strand cDNA was generated using DNA polymerase I. The cDNA fragments were purified and washed for end repair and ligated to sequencing adapters. The cDNA fragments of suitable size were purified and enriched by PCR to obtain the final cDNA library. The cDNA library was sequenced using Illumina HiSeq equipment (Illumina, USA). Clean reads were selected after removing low-quality sequences, adapter sequences, and some ambiguous bases ' $N$ '. The remaining high-quality reads were filtered for short reads below 25 bp, and repeat sequences were masked before assembling. The clean reads were de novo assembled using Trinity with default K-mers $=25$ [73]. Contigs were obtained by conjoining the K-mers in an unambiguous path. Then, the reads were mapped back to contigs to construct unigenes with the paired-end information. Finally, the overlapping unigenes from the six libraries were assembled into a continuous sequence, and redundant sequences were removed to acquire non-redundant unigenes that were as long as possible.

The sequences of mapping markers on chromosomes 1 and 4 were aligned to the transcript sequencing database. Candidate gene prediction was performed using GO, Pfam, Swissprot, and nr annotation.

\section{Abbreviations}

CMV: Cucumber Mosaic Virus; DCL: Dicer-like; EST-SSR: Expressed sequence tag-Simple sequence repeats; ETI: Effector-triggered immunity; FSH1: serine hydrolase; KASP: Kompetitive allele-specific PCR; LG: Linkage group; LTR: Long terminal repeat; LRRs: Leucine-rich repeats; MLOD: Modified logarithm of odds; NBS: Nucleotide-binding site; NGS: Next-generation sequencing; PAMPS: Pathogen-associated molecular patterns; QTL: Quantitative trait locus; R gene: Resistance gene; Recombinant inbred lines: RILs; SLAF: Specific Length Amplified Fragment; SNP: Single nucleotide polymorphism; SRAP: Sequence related amplified polymorphism; VPg: potyviral genome-linked protein

\section{Declarations}

\section{Ethics approval and consent to participate}

Not applicable

\section{Consent for publication}

All the authors consent to publish.

\section{Availability of data and materials}

The datasets generated and analyzed during this study are available from the first and corresponding author on reasonable request. 


\section{Competing interests}

The authors declare that they have no competing interests.

\section{Funding}

This study was funded by the National Natural Science Foundation of China (No. 31501778).

\section{Authors' contributions}

Lou L designed, performed, analyses and drafted the experiments. With valuable suggestions by Su X as well as technical assistance by Liu Z and Liu X. All authors read and approved the manuscript.

\section{Acknowledgements}

We thank Dr. Jeroen A. Berg for valuable suggestions during the preparation of the manuscript. We also acknowledge the reviewers for their constructive comments to improve the manuscript. We would give thanks to Biomarker Technologies Co., Ltd., Beijing for technical support in bioinformatics. Also we would like to thank Biomics (Beijing) Biotech Co. Ltd for providing funding for the RNA-seq data.

\section{Authors' information}

All authors work at Institute of Vegetable Crops, Jiangsu Academy of Agricultural Sciences/Laboratory for Horticultural Crop Genetic Improvement, Nanjing, Jiangsu Province, 210014, China.

\section{References}

1. Oboh IO, Aluyor EO. Luffa cylindrical-an emerging cash crop. Afr. J. Agric. Res. 2009; 4:684-688.

2. Rabei S, Rizk RM, Khedr AHA. Keys for and morphological character variation in some Egyptian cultivars of Cucurbitaceae. Genet. Resour. Crop Evol. 2013; 60:1353-1364. doi:10.1007/s10722-012-9924-5

3. Prakash K, Pandey A, Radhamani J, Bisht IS. Morphological variability in cultivated and wild species of Luffa (Cucurbitaceae) from India. Genet Resour Crop Evol. 2013; 60: 2319-2329. doi:10.1007/s10722-013-9999-7

4. Jamwal M and Sharma N. Reproductive efficiency of two Luffa Species-Factors affecting low reproductive rate in meiotically stable Luffa acutangula (L.) Roxb. Nucleus. 2015; 58:59-65.

5. Shahidi A, Jalilnejad N, Jalilnejad E. A study on adsorption of cadmium( () ions from aqueous solution using Luffa cylindrical. Desalin.Water. Treat. 2015; 53:3570-3579.

6. Papanicolaou GC, Psarra E, Anastasiou D. Manufacturing and mechanical response optimization of epoxy resin/Luffa cylindrical composite. J Appl Polym Sci. 2015; 132:41992. https://doi.org/10.1002/app.41992

7. Dairo FAS, Aye PA, Oluwasola TA. Some functional properties of loofah gourd (Luffa cylindrical L., M. J. Roem) seed. J Food Agric Environ. 2007; 5:97101.

8. Fernandes LCB, Cordeiro LAV, Soto-Blanco B. Luffa acutangula Roxb. tea promotes developmental toxicity to rats. J Anim Vet Adv. 2010; 9:1255-1258.

9. Shang LH, Li CM, Yang ZY, Che DH, Cao JY, Yu Y. Luffa echinata Roxb. Induces human colon cancer cell (HT-29) death by triggering the mitochondrial apoptosis pathway. Molecules.2012; 17:5780-5794.

10. Cui J, Cheng J, Wang G, Tang X, Wu Z, Lin M, et al. QTL analysis of three flower-related traits based on an interspecific genetic map of Luffa. Euphytica. 2015; 202: 45-54. Doi:10.1007/s10681-014-1208-z.

11. Wu H, He X, Gong H, Luo S, Li M, Chen J, et al. Genetic linkage map construction and QTL analysis of two interspecific reproductive isolation traits in sponge gourd. Front Plant Sci. 2016; 7:980. doi: 10.3389/fpls.2016.00980

12. Sun X, Liu D, Zhang X, Li W, Liu H, Hong W, et al. SLAF-seq: an efficient method of large-scale de novo SNP discovery and genotyping using highthroughput sequencing. PLoS One. 2013; 8: e58700. doi: 10.1371/journal.pone.0058700

13. Zhang Y, Wang L, Xin H, Li D, Ma C, Ding X, et al. Construction of a high-density genetic map for sesame based on large scale marker development by specific length amplified fragment (SLAF) sequencing. BMC Plant Biol. 2013; 13:141.

14. Qi Z, Huang L, Zhu R, Xin D, Liu C, Han X, et al. A high-density genetic map for soybean based on specific length amplified fragment sequencing. PLoS ONE. 2014; 9: 104871.

15. Li B, Tian L, Zhang J, Hung L, Han F, Yan S, et al. Construction of a high-density genetic map based on large-scale markers developed by specific length amplified fragment sequencing (SLAF-seq) and its application to QTL analysis for isoflavone content in Glycine max. BMC Genomics. 2014; $15: 1086$.

16. Zhang J, Zhang Q, Cheng T, Yang W, Pan H, Zhong J, et al. High-density genetic map construction and identification of a locus controlling weeping trait in an ornamental woody plant (Prunus mume Sieb. et Zucc). DNA Res. 2015; 22: 183-191. Doi:10.1093/dnares/dsv003 
17. Wei Q, Wang Y, Qin X, Zhang Y, Zhang Z, Wang J, et al. An SNP-based saturated genetic map and QTL analysis of fruit-related traits in cucumber using specific-length amplified fragment (SLAF) Sequencing. BMC Genomics. 2014; 15: 1158.doi:10.1186/1471-2164-15-1158

18. Xu X, Xu R, Zhu B, Yu T, Qu W, Lu L, et al. A high-density genetic map of cucumber derived from specific length amplified fragment sequencing (SLAF-seq). Front Plant Sci. 2015; 5: 768.doi:10.3389/fpls.2014.00768

19. Jiang B, Liu W, Xie D, Peng Q, He X, Lin Y, et al. High-density genetic map construction and gene mapping of pericarp color in wax gourd using specificlocus amplified fragment (SLAF) sequencing. BMC Genomics.2015;16:1035. Doi:10.1186/s12864-015-2220-y.

20. He Y, Yuan W, Dong M, Han Y, Shang F. The first genetic map in sweet osmanthus (Osmanthus fragrans Lour.) using specific locus amplified fragment sequencing. Fronti Plant Sci. 2017; 8:1621. Doi:10.3389/fpls.2017.01621.

21. Jacquemond M. Chapter 13 - Cucumber mosaic virus. Adv Virus Res. 2012; 84:439-504. https://doi.org/10.1016/B978-0-12-394314-9.00013-0

22. Rani A, Jansirani P, Rabindran R. Screening and identification of ridge gourd [ Luffa acutangula (L.) Roxb] genotypes against Cucumber mosaic virus (CMV) tolerance. Int.J.Curr.Microbiol.App.Sci., 2017; 6: 119-127. doi: 10.20546 /ijcmas.2017.603.013

23. West MAL, van Leeuwen H, Kozik A, Kliebenstin DJ, Doerge RW, St Clair DA, et al. High-density haplotyping with microarray-based expression and single feature polymorphism markers in Arabidopsis. Genome Res. 2006; 16:787-795.doi:10.1101/gr.5011206

24. Hyten DL, Cannon SB, Song Q, Weeks N, Fickus EW, Shoemaker RC, et al. High-throughput SNP discovery through deep resequencing of a reduced representation library to anchor and orient scaffolds in the soybean whole genome sequence. BMC Genomics. 2010;11:38.

https://doi.org/10.1186/1471-2164-11-38.

25. Shifman S, Bell JT, Copley RR, Taylor MS, Williams RW, Mott R, et al. A high-resolution single nucleotide polymorphism genetic map of the mouse genome. PLoS Biol. 2006; 4:395. DOI: 10.1371/journal.pbio.0040395

26. Su XJ, Xu H, Chen LZ, Song B, Yuan YH, Chen JF. Analysis on the phylogenetic relationship of Luffa (Luffa cylindrical (L.) Roem.) germplasm based on ISSR. J Nanjing Agric Univ. 2010; 33:42-46.

27. Lapidot M, Paran I, Ben-Joseph R, Ben-Harush S, Pilowsky M, Cohen S, Shifriss C. Tolerance to Cucumber mosaic virus in pepper: development of advanced breeding lines and evaluation of virus level. Plant Dis. 1997; 81:185-188.

28. Takahashi H, Miller J, Nozaki Y, Sukamto,Takeda M, Shah J, et al. RCY1, an Arabidopsis thaliana RPP8/HRT family resistance gene, conferring resistance to cucumber mosaic virus requires salicylic acid, ethylene and a novel signal transduction mechanism. Plant J. 2002; 32:655-667.

29. Seo YS, Rojas M, Lee JY, Lee SW, Jeon JS, Ronald P, et al. A viral resistance gene from common bean functions across plant families and is up-regulated in a non-virus-specific manner. PNAS. 2006; 103:11856-11861.

30. Kang WH, Hong NH, Yang HB, Kwon JK, Jo SH, Seo JK, et al. Molecular mapping and characterization of a single dominant gene controlling CMV resistance in peppers (Capsicum annuum L.). Theor Appl Genet. 2010; 120: 1587-1596. DOI: 10.1007/s00122-010-1278-9

31. Yoshii M, Yoshioka N, Ishikawa M, Naito S. Isolation of an Arabidopsis thaliana mutant in which the multiplication of both Cucumber Mosaic virus and Turnip Crinkle virus is affected. J Virol. 1998; 72:8731-8737.

32. Yoshii M, Nishikiori M, Tomita K, Yoshioka N, Kozuka R, Naito S, et al. The Arabidopsis cucumovirus multiplication 1 and 2 loci encode translation initiation factors 4E and 4G. J Virol. 2004; 78:6102-6111.

33. Chaim AB, Grube RC, Lapidot M, Jahn M, Paran I. Identification of quantitative trait loci associated with resistance to cucumber mosaic virus in Capsicum annuum. Theor Appl Genet. 2001; 102:1213-1220.

34. Caranta C, Pflieger S, Lefebvre V, Daubèze AM, Thabuis A, Palloix A. QTLs involved in the restriction of cucumber mosaic virus (CMV) long-distance movement in pepper. Theor Appl Genet. 2002; 104:586-591.

35. Yao M, Li N, Wang F, Ye Z. Genetic analysis and identification of QTLs for resistance to cucumber mosaic virus in chili pepper (Capsicum annuum L.). Euphytica. 2013; 193:135-145.doi:10.1007/s10681-013-0953-8

36. Valkonen JPT, Watanabe KN. Autonomous cell death, temperature sensitivity and the genetic control associated with resistance to cucumber mosaic virus (CMV) in diploid potatoes (Solanum spp). Theor Appl Genet. 1999; 99:996-1005.

37. Munshi AD, Panda B, Mandal B, Bisht IS, Rao ES, Kumar R. Genetics of resistance of cucumber mosaic virus in Cucumis sativus var. hardwickii R. Alef. Euphytica. 2008; 164:501-507. DOI 10.1007/s10681-008-9741-2.

38. Karchi Z, Cohen S, Govers A. Inheritance of resistance to Cucumber Mosaic virus in melons. Phytopathology.1975; 65:479-481.

39. Dogimont C, Leconte L, Périn C, Thabuis A, Lecoq H, Pitrat M. Identification of QTLs contributing to resistance to different strains of cucumber mosaic cucumovirus in melon. Acta Hort. 2000; 510:391-398.

40. Guiu-Aragonés C, Monforte AJ, Saladié M, Corrêa RX, Garcia-Mas J, Martín-Hernández AM. The complex resistance to cucumber mosaic cucumovirus (CMV) in the melon accession PI161375 is governed by one gene and at least two quantitative trait loci. Molecular Breeding. 2014; 34:351-362.

41. Lecoq H, Pochard E, Pitrat M, Laterrot $\mathrm{H}$, Marchoux G. Identification et exploitation de résistances aux virus chez les plantes maraîchères. Cryptog Mycol. $1982 ; 3: 333-345$

42. Caranta C, Palloix A, Lefebvre V, Daubèze AM. QTLs for a component of partial resistance to cucumber mosaic virus in pepper: restriction of virus installation in host-cells. Theor Appl Genet. 1997; 94:431-438. DOI: 10.1007/s001220050433

43. Nono-Wondim R, Gebre-Selassie K, Palloix A, Pochard E, Marchoux G. Study of multiplication of cucumber mosaic virus in susceptible and resistant Capsicum annuum lines. Ann Appl Biol. 1993; 122:49-56.

44. Dufour O, Palloix A, Gebre-Selassie K, Pochard E, Marchoux G. The distribution of cucumber mosaic virus in resistant and susceptible plants of pepper. Can J Bot. 1989; 67:655-660. 
45. Diaz-Pendon JA, Truniger V, Nieto C, Garcia-mas J, Bendahmane A, Aranda MA. Advances in understanding recessive resistance to pant viruses. Mol plant pathol. 2004; 5: 223-233. doi: 10.1111/j.1364-3703.2004.00223.x.

46. Duprat A, Caranta C, Revers F, Menand B, Browning KS, Robaglia C. The Arabidopsis eukaryotic initiation factor (iso)4E is dispensable for plant growth but required for susceptibility to potyviruses. Plant J. 2002; 32: 927-934.

47. Hwang J, Li J, Liu WY, An SJ, Cho H, Her NH, et al. Double mutations in elF4E and elFiso4E confer recessive resistance to Chilli veinal mottle virus in pepper. Mol. Cells. 2009; 27: 329-336. doi: 10.1007/s10059-009-0042-y

48. Ling KS, Harris KR, Meyer JDF, Levi A, Guner N, Wehner TC, et al. Non-synonymous single nucleotide polymorphisms in the watermelon elF4E gene are closely associated with resistance to Zucchini yellow mosaic virus. Theor. Appl. Genet. 2009; 120: 191-200.

49. Ruffel S, Gallois JL, Moury B, Robaglia C, Palloix A, Caranta C. Simultaneous mutations in translation initiation factors elF4E and elF(iso)4E are required to prevent pepper veinal mottle virus infection of pepper. J. Genet. Virol. 2006; 87:2089-2098.

50. Sato M, Nakahara K, Yoshii M, Ishikawa M, Uyeda I. Selective involvement of members of the eukaryotic initiation factor $4 \mathrm{E}$ family in the infection of Arabidopsis thaliana by potyviruses. FEBS Lett. 2005; 579: 1167-1171.

51. Mazier M, Flamain F, Nicolaï M, Sarnette, V. and Caranta, C. Knockdown of both elF4E1 and elF4E2 genes confers broad-spectrum resistance against potyviruses in tomato. PLoS One. 2011; 6: e29595.

52. Rodríguez-Hernández AM, Gosalvez B, Sempere RN, Burgos L, Aranda MA, Truniger V. Melon RNA interference (RNAi) lines silenced for Cm-elF4E show broad virus resistance. Mol. Plant Pathol. 2012; 13:755-763.

53. Chandrasekaran J, Brumin M, Wolf D, Leibman D, Klap C, Pearlsman M, et al. Development of broad virus resistance in non-transgenic cucumber using CRISPR/Cas9 technology. Mol Plant Pathol. 2016; 17: 1140-1153.

54. Requena A, Simón-Buela L, Salcedo G, García-Arenal F. Potential involvement of a cucumber homolog of phloem protein 1 in the long-distance movement of Cucumber mosaic virus particles. Mol Plant Microbe Interact. 2006; 19:734-746.

55. Deyoung BJ, Innes RW. Plant NBS-LRR proteins in pathogen sensing and host defense. Nat. Immunol. 2006; 7:1243-1249.

56. Chisholm ST, Coaker G, Day B, Staskawicz BJ. Host-microbe interactions: shaping the evolution of the plant immune response, Cell. 2006 ; $124: 803-814$.

57. Takahashi H, Goto N, Ehara Y. Hypersensitive response in cucumber mosaic virus-inoculated Arabidopsis thaliana, Plant J. $1994 ; 6$ : 369-377.

58. Bouché N, Lauressergues D, Gasciolli V, Vaucheret H. An antagonistic function for Arabidopsis DCL2 in development and a new function for DCL4 in generating viral siRNAs. EMBO J. 2006; 25:3347-3356.

59. Diaz-Pendon JA, Li F, Li WX, Ding SW. Suppression of antiviral silencing by cucumber mosaic virus $2 \mathrm{~b}$ protein in Arabidopsis is associated with drastically reduced accumulation of three classes of viral small interfering RNAs. Plant Cell 2007;19: 2053-2063.

60. Harvey JJW, Lewsey MG, Patel K, Westwood J, Heimstädt S, Carr JP, et al. An antiviral defense role of AG02 in Plants. PLoS One. $2011 ; 6:$ 14639.

61. Wang XB, Jovel J, Udomporn P, Wang Y, Wu QF, Li WX, et al. The 21-nucleotide, but not 22-nucleotide, viral secondary small interfering RNAs direct potent antiviral defense by two cooperative Argonautes in Arabidopsis thaliana. Plant Cell. 2011; 23: 1625-1638.

62. Garcia-Ruiz H, Takeda A, Chapman EJ, Sullivan CM, Fahlgren N, Brempelis KJ, et al. Arabidopsis RNA-dependent RNA polymerases and dicer-like proteins in antiviral defense and small interfering RNA biogenesis during Turnip Mosaic Virus infection. Plant Cell. 2010; 22:481-496.

63. Wang XB, Wu QF, Ito T, Cillo F, Li WX, Chen XM, et al. RNAi-mediated viral immunity requires amplification of virus-derived siRNAs in Arabidopsis thaliana. PNAS. 2010; 107: 484-489.

64. Gao H, Yang M, Yang H, Qin Y, Zhu B, Xu G, et al. Arabidopsis ENOR3 regulates RNAi-mediated antiviral defense. J Genet Genomics. 2018; $45: 33-40$.

65. Boeke JD, Corces VG. Transcription and reverse transcription of retrotransposons. Annu. Rev. Microbiol. 1989; 43:403-434.

66. Pouteau S, Grandbastien MAG, Boccara M. Microbial elicitors of plant defence responses activate transcription of a retrotransposon. Plant J. 1994; 5:535-542.

67. Grandbastien, MA, Audeon C, Casacuberta JM, Grappin P, Lucas H, Moreau C et al. Functional analysis of the tobacco Tnt1 retrotransposon. Genetica. 1994; 93:181-189.

68. Moreau-mhiri C, Morel JB, Audeon C, Ferault M, Grandbastien MA, Lucas H. Regulation of expression of the tobacco Tnt1 retrotransposon in heterologous species following pathogen-related stresses. Plant J. 1996; 9:409-419.

69. Saghai-Maroof MA, Soliman KM, Jorgensen RA, Allard RW. Ribosomal DNA spacer-length polymorphisms in barley: mendelian inheritance, chromosomal location, and population dynamics. Proc. Natl. Acad. Sci. USA. 1984; 81: 8014-8018. Doi:10.1073/pnas.81.24.8014.

70. Bos L. Crop losses caused by viruses. Crop Prot. 1982; 1:263-282.

71. Kent W J. BLAT-the BLAST-like alignment tool. Genome Res. 2002;12: 656-664. doi: 10.1101/gr.229202.

72. Liu D, Ma C, Hong W, Huang L, Liu M, Liu H, et al. Construction and analysis of high-density linkage map using high-throughput sequencing data. PLoS One. 2014; 9: e98855. doi: 10.1371/journal.pone.0098855.

73. Grabherr MG, Haas BJ, Yassour M, Levin JZ, Thompson DA, Amit I, et al. Full-length transcriptome assembly from RNA-Seq data without a reference genome. Nat Biotechnol. 2011; 29: 644-652.

\section{Tables}

Table 1. Summary of SLAF markers. 


\begin{tabular}{llll}
\hline Samples & SLAF Number & Total depth & Average depth \\
\hline P2-16 & 88,606 & $5,153,236$ & 58.16 \\
P1-21 & 89,434 & $5,596,706$ & 62.58 \\
\hline Offspring & 68,636 & 842,043 & 12.27 \\
\hline
\end{tabular}

Notes: Total Depth: Mapped Reads; Average depth: Number of reads per SLAF;

Offspring: Average value of all offspring for each parameter per sample.

Table 2. Basic information of sponge gourd genetic map.

\begin{tabular}{lllll}
\hline Linkage & Marker number & Map & Marker interval (cM) & Max \\
& \multicolumn{5}{c}{ length (cM) } & distance (cM) \\
\hline LG1 & 380 & 124.00 & 0.33 & 4.01 \\
LG2 & 348 & 118.78 & 0.34 & 4.40 \\
\hline LG3 & 252 & 114.95 & 0.46 & 3.03 \\
\hline LG4 & 269 & 119.84 & 0.45 & 3.31 \\
\hline LG5 & 329 & 102.80 & 0.31 & 4.01 \\
\hline LG6 & 275 & 119.91 & 0.44 & 4.64 \\
\hline LG7 & 379 & 111.50 & 0.30 & 2.77 \\
\hline LG8 & 191 & 91.71 & 0.48 & 3.78 \\
\hline LG9 & 315 & 143.28 & 0.45 & 4.09 \\
\hline LG10 & 98 & 113.91 & 1.16 & 4.86 \\
\hline LG11 & 322 & 126.80 & 0.39 & 3.27 \\
\hline LG12 & 271 & 97.70 & 0.36 & 2.93 \\
\hline LG13 & 272 & 133.40 & 0.49 & 4.40 \\
\hline Total & 3,701 & 1518.56 & 0.41 & 4.86 \\
\hline
\end{tabular}

Table 3. The double crossover and missing percent of all the linkage groups.

\begin{tabular}{ccc}
\hline Linkage & Double crossover percent (\%) & Missing percentage (\%) \\
\hline LG1 & 0.04 & 0.68 \\
LG2 & 0.03 & 0.54 \\
\hline LG3 & 0.05 & 1.15 \\
\hline LG4 & 0.02 & 0.77 \\
\hline LG5 & 0.04 & 0.79 \\
\hline LG6 & 0.04 & 0.55 \\
\hline LG7 & 0.03 & 0.39 \\
\hline LG8 & 0.07 & 0.93 \\
\hline LG9 & 0.04 & 0.95 \\
\hline LG10 & 0.18 & 2.23 \\
\hline LG11 & 0.03 & 0.57 \\
\hline LG12 & 0.10 & 1.48 \\
\hline LG13 & 0.03 & 0.99 \\
\hline
\end{tabular}


Table 4. The significant level of CMV resistance markers in the genetic linkage groups of the Luffa $F_{2: 3}$ populations.

\begin{tabular}{ccccc}
\hline Linkage Group & Genetic position (cM) & SNP markers & KASP markers & P value \\
\hline 1 & 100.457 & Marker 7731 & A009529 & $0.0030^{* *}$ \\
\hline 1 & 100.457 & Marker 5105 & A009530 & $0.0030^{* *}$ \\
\hline 1 & 100.457 & Marker 9318 & A009533 & $0.0045^{* *}$ \\
\hline 1 & 100.457 & Marker 18971 & A009534 & $0.0030^{* *}$ \\
\hline 1 & 100.457 & Marker 58975 & A009540 & $0.0030^{* *}$ \\
\hline 1 & 100.457 & Marker 18364 & A009544 & $0.0030^{* *}$ \\
\hline
\end{tabular}

** Significant at 0.01

Table 5. The sequences of KASP marker primers.

\begin{tabular}{|c|c|c|c|c|c|c|}
\hline $\begin{array}{c}\text { SNP } \\
\text { marker }\end{array}$ & $\begin{array}{l}\text { KASP } \\
\text { marker }\end{array}$ & Primer_AlleleX & Primer_AlleleY & Primer_Common & AlleleX & Alle] \\
\hline $\begin{array}{c}\text { Marker } \\
7731\end{array}$ & A009529 & ATGAGTGAGGGAACAGAAAGATG & ATGAGTGAGGGAACAGAAAGATA & AGTCTTTACGGGTTAGCCTACAAAT & $\mathrm{C}$ & $\mathrm{T}$ \\
\hline $\begin{array}{c}\text { Marker } \\
5105\end{array}$ & A009530 & GGGGAGTGCCTAAACCTCTT & GGGGAGTGCCTAAACCTCTA & CATCCGTAAGCTCACATTTCCTG & A & $\mathrm{T}$ \\
\hline $\begin{array}{c}\text { Marker } \\
9318\end{array}$ & A009533 & CAAGAAAAAAACTCTCATTTACСАTTGTC & CCAAGAAAAAAACTCTCATTTACСATTGTT & CTGGAAGCACGAAAAGTTAGGGTTTTTTA & G & A \\
\hline $\begin{array}{c}\text { Marker } \\
18971\end{array}$ & A009534 & GAGTCGTAAGTTGTATGGCGCTA & AGTCGTAAGTTGTATGGCGCTG & TCCAACATCTCTTTCTCAGAGACAATGTA & $\mathrm{T}$ & $\mathrm{C}$ \\
\hline $\begin{array}{l}\text { Marker } \\
58975\end{array}$ & A009540 & CTGTAGATGACCCTTTTGTAATTGCG & CTGTAGATGACCCTTTTGTAATTGCA & AGTGTCCATCTTAAATTCTGGGCATCA & $\mathrm{C}$ & $\mathrm{T}$ \\
\hline $\begin{array}{c}\text { Marker } \\
18364\end{array}$ & A009544 & AGCAAAACTTTTTATGAAAATGGTTTATCTT & GCAAAACTTTTTATGAAAATGGTTTATCTC & TCTCATACATTGAAAAAGGACATGAAAAG & $\mathrm{T}$ & $\mathrm{C}$ \\
\hline
\end{tabular}

\section{Figures}




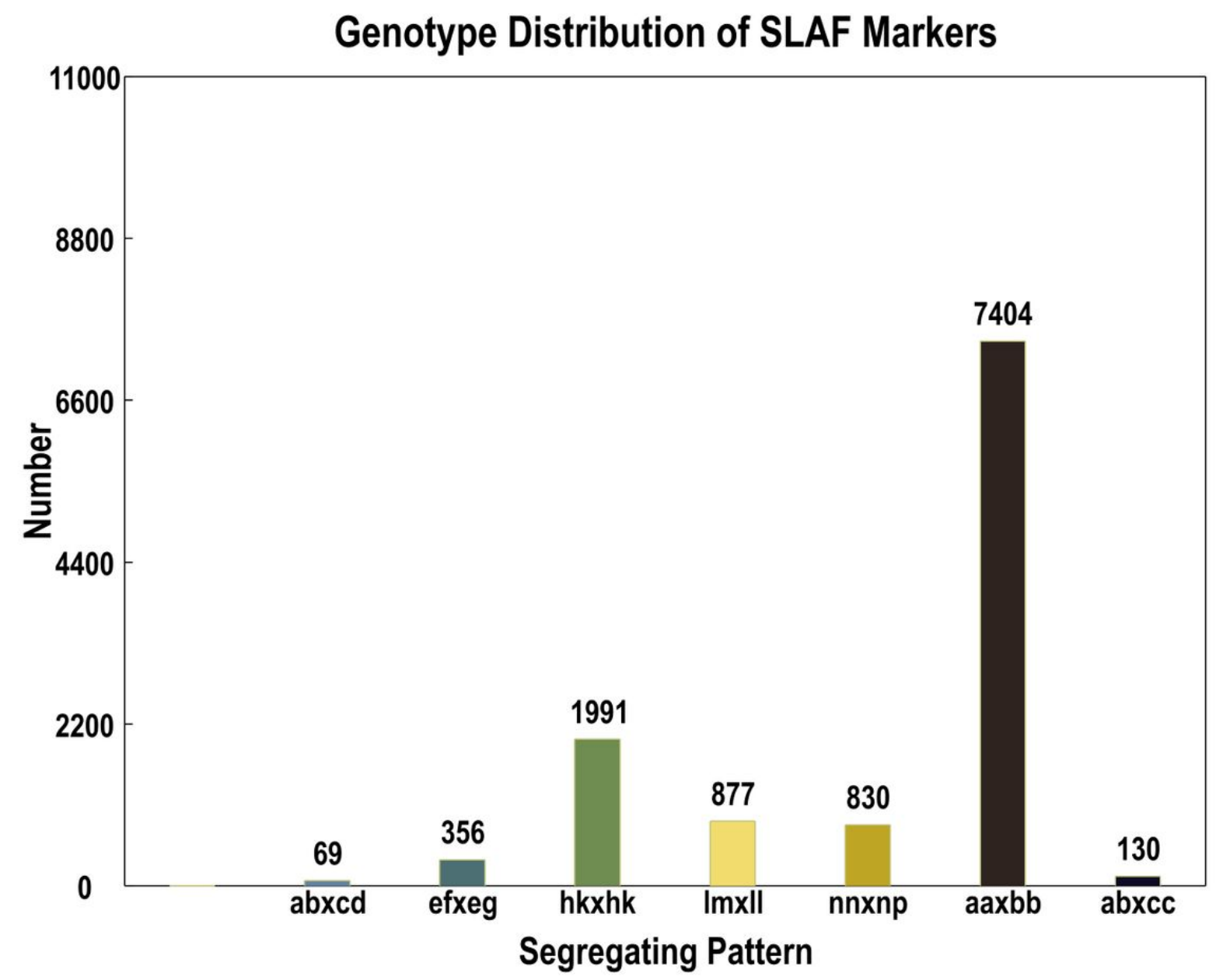

Figure 1 

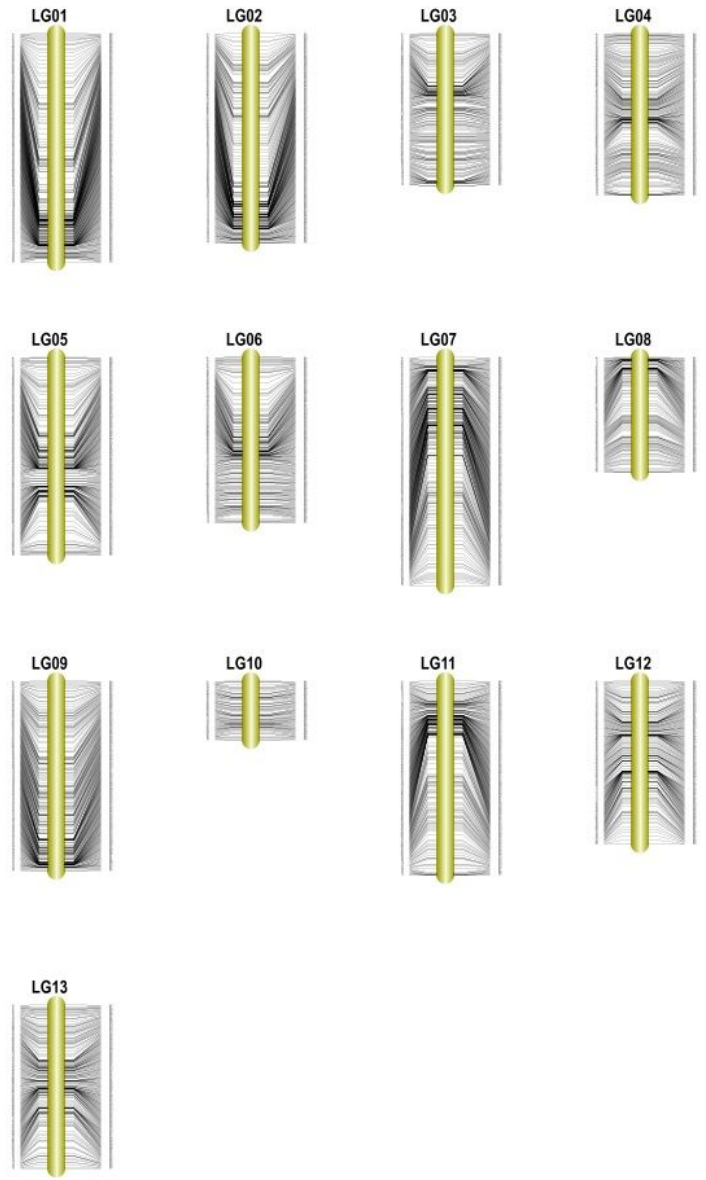

Figure 2 

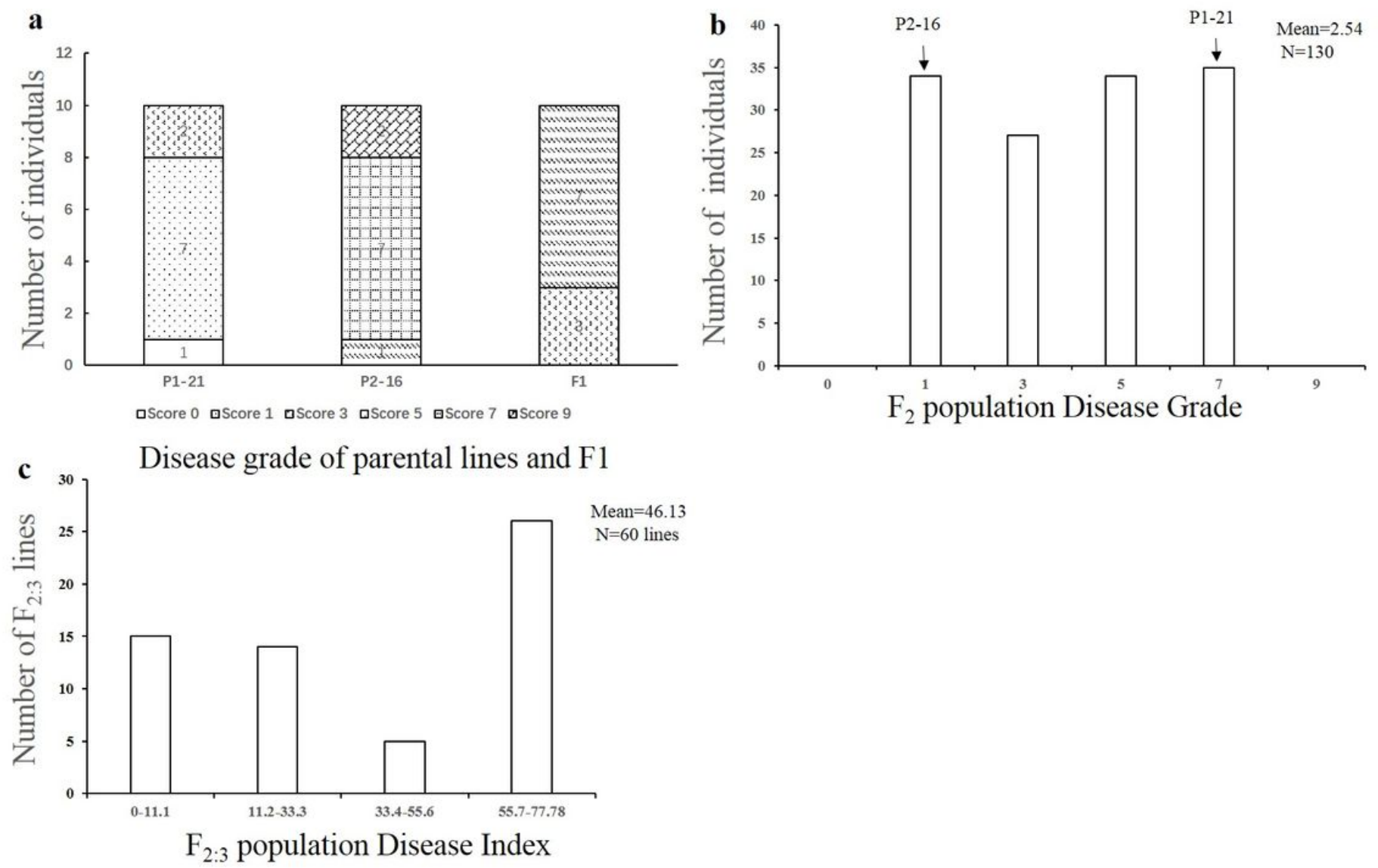

Figure 3

LG 1

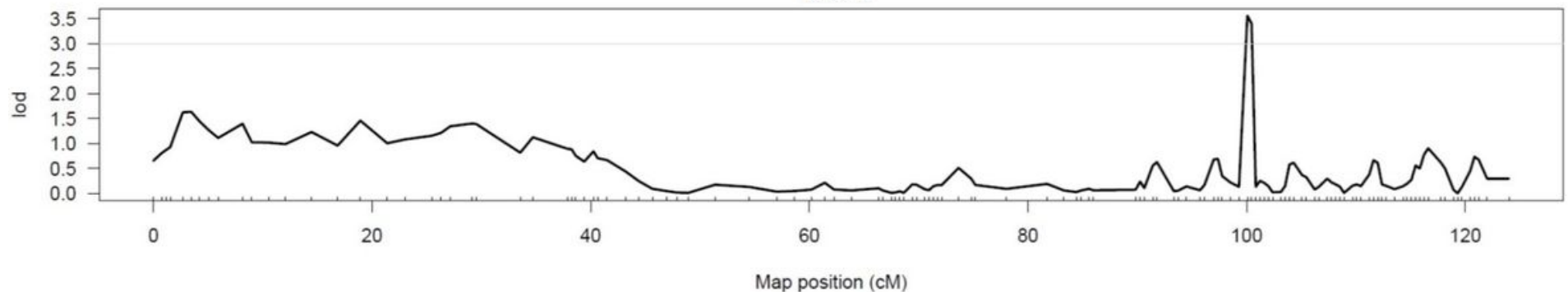

LG 4

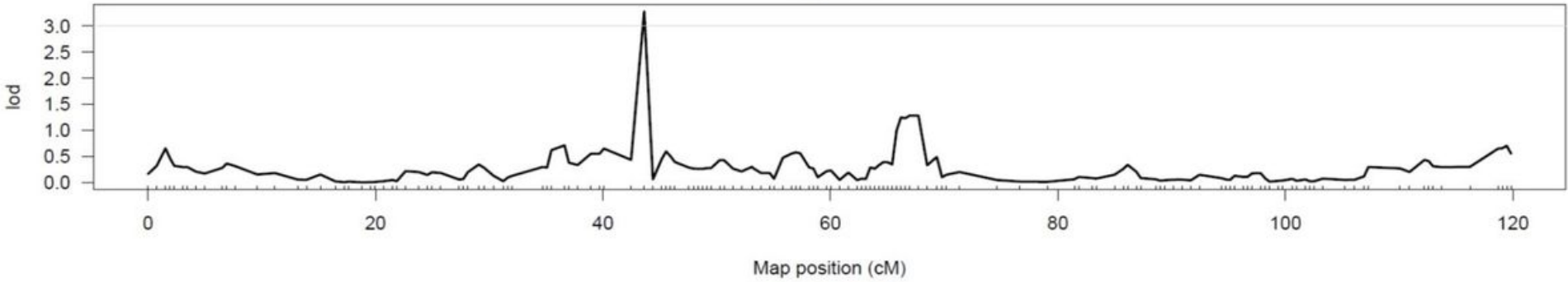

Figure 4 


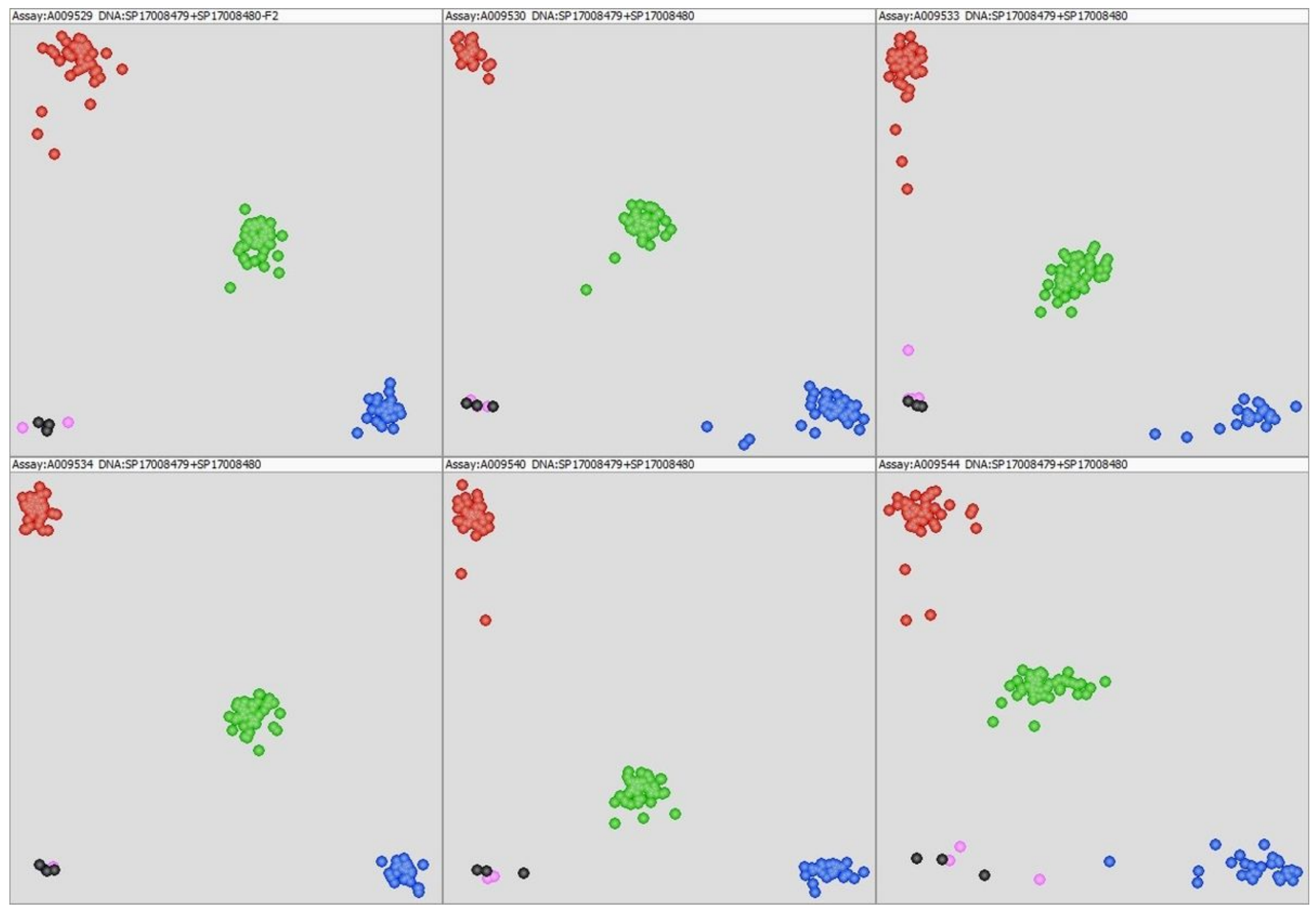

Figure 5 


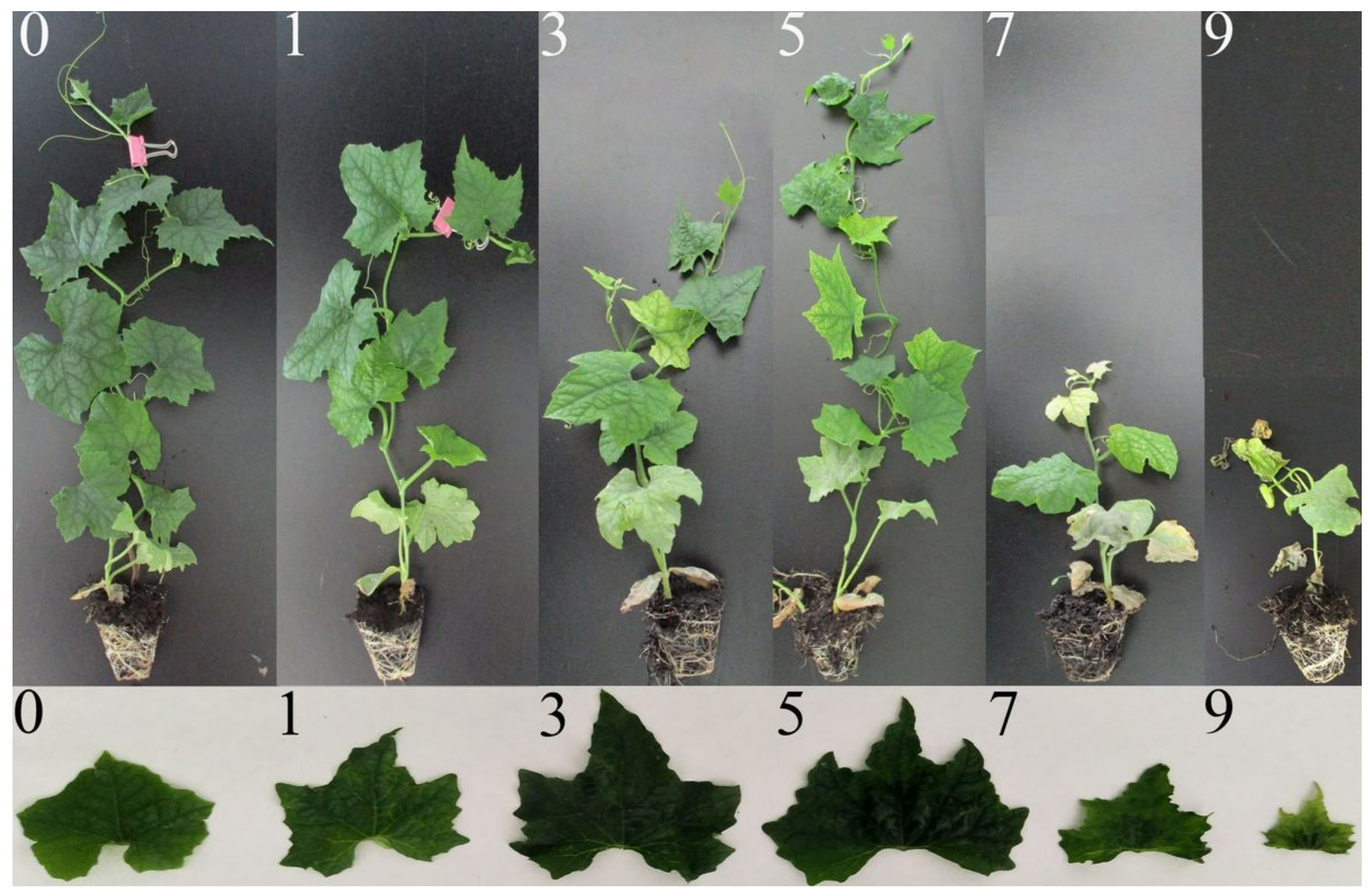

Figure 6

\section{Supplementary Files}

This is a list of supplementary files associated with this preprint. Click to download.

- Additionalfile8.xlsx

- Additionalfile4.xlsx

- Additionalfile3.jpg

- Additionalfile6.pdf

- Additionalfile2.xlsx

- Additionalfile1.xlsx

- Additionalfile5.pdf

- Additionalfile7.xlsx 